\section{Classical Mechanics}

By Dr. D. E. Rutherford. (University Mathematical Texts.) Pp. viii + 200. (Edinburgh and London: Oliver and Boyd, Ltd.; New York: Interscience Publishers, Inc., 1951.) 10s. 6d. net.

$\mathrm{D}$ R. D. E. RUTHERFORD'S aim is to provide a concise and unified account of classical theoretical mechanics from the beginning up to Hamilton's principle. There are five chapters, dealing respectively with kinematics, the nature of force, dynamics of a particle, dynamics of rigid bodies and generalized co-ordinates. A surprisingly large amount of information has been packed into a small space. For example, Chapter 4 contains not only the usual elementary theorems on rigid dynamics, and an account of Euler's equations and the top, but also some statics, including centre of gravity, Poinsot's central axis and virtual work. Chapter 5 includes Lagrange's equations, normal modes of oseillation, stability, Hamilton's equations and Hamilton's principle. There are examples for solution at the end of each chapter, the total number being 108, and an index.

There can be no doubt as to the value of the matter contained in the book; but it is rather puzzling to know for what type of student it is intended. The introduction points out that a knowledge of calculus, co-ordinate geometry, and vectors is required. It does not mention that p. 141 uses the notation and two theorems of matrix theory. Also there is no statement as to the previous knowledge of dynamics required; but it is obvious that a beginner will find great difficulty with some of the early pages-for example, p. 13 on moving axes. The introduction stresses that the book is arranged in logical order and not in order of increasing difficulty, and that "many readers may find it advisable, therefore, to read the various sections in an order other than that in which they are presented. Teachers will, no doubt, advise their students on this point according to the students' maturity". This last sentence transfers the task of presenting the subject in a form that can be easily assimilated from the author's to other shoulders. H. T. H. Praggio

\section{The Cold Working of Non-Ferrous Metals and Alloys}

A Symposium on Metallurgical Aspects of the subject held in London on the occasion of the Annual General Meeting of the Institute, 14 March 1951. (Institute of Metals Monograph and Report Series, No. 12.) Pp. 207. (London: Institute of Metals, 1952.) $15 s$.

THE five papers which make up this symposium are reviews of particular aspects of cold-working, such as wire-drawing, cold-rolling and pressing. The practical techniques employed are examined in relation to the optimum process conditions for the more commonly used non-ferrous metals and alloys, with the fundamental aspects of cold-working reviewed in one general introductory paper. This may represent a just proportion in a work on applied metallurgy, but even in this paper the discussion is not extended to cover any detailed theory. The interpretation of cold-working phenomena in terms of dislocations, and the treatment given of deformation textures, are both so generalized that they give no more than a brief indication of current ideas. This is unavoidable in the space of the few pages devoted to these subjects, and the selection of the material, which must have been a difficult task, is, on the whole, well judged. The volume is clearly a most useful work for those actively connected with industrial processes which involve cold-working in any form. Most problems are touched upon, and where detail is inadequate the quoted references may be followed up. However, as the development and extension of such techniques depend upon a fuller understanding of the metallurgy and physics of the deformation mechanisms, a closer consideration of fundamentals would have widened its appeal.

A. J. KenNELY

Entwicklungsphysiologie

Von L. v. Ubisch. Pp. $85+16$ plates. (Berlin : F. W. Peters, 1952.) n.p.

DROF. VON UBISCH has made important contributions to the experimental embryology of a wide variety of forms-echinoderms, ascidians, Ascaris and amphibians among them. He has, however, stood somewhat outside the major schools, such as the German, the Swedish and the Belgian, which have tended to dominate the subject in the past few decades, and his contributions have perhaps received rather less attention than was their due. It is therefore all the more gratifying to have from his pen a general treatment of the field. His little book is exceedingly short and is aimed at a student audience. Its brevity has enforced a most admirable clarity of theoretical outlook. Von Ubisch presents a very modern point of view : that the essential basis of differentiation is to be sought in the interaction between nuclei and locally differentiated cytoplasms, by which different sets of genes become activated or inhibited. In the space at his disposal the author can do little more than adumbrate this proposition and has had to forgo a discussion of much of the widely diversified evidence which bears on it, particularly from the side of genetics. However, little of major importance is omitted from his summary of the facts of experimental embryology, and his book is probably the best short and up-to-date account of it.

C. H. WADDINGTON

Leibniz und das Reich der Gnade

Von Kurt Hildebrandt. Pp. viii +505. (Haag: Martinus Nijhoff, 1953.) 26.50 guilders.

CONTEMPORARY scholarship may perhaps be I said to have 're-discovered' Leibniz ; the stately volume here under review is not the only evidence of this trend in recent months, but it is a contribution of a somewhat special character, designed to set the great thinker at the centre of a specifically European philosophy, occidental in spirit and intended to be "understanded of the people". To this extent, it represents a return to the early Greek concept, when the love of wisdom was taught not so much as an academic subject, as a life to be lived. Thus, a not inappropriate rendering of the title of the present work might be "Leibniz and the Realm of Grace".

The first part is largely biographical, including the encounters with Locke and Newton. Next follows a typical Systematik, an assessment of the creative faculty in mankind, and the problem of good and evil. (The celebrated "Theodicy" comes in for attention earlier.) Finally, there is the inevitable discussion of action and re-action, including questions of belief and configuration. The latter should not be confused with the Gestalt of to-day; for Leibniz, 'shape' was more of an abstraction than it is to us. The book - a work of real distinction-concludes with a useful chronological table. F. I. G. RawLIns 